\title{
A mudança de paradigma em sociologia urbana: do paradigma ecológico ao socioespacial ${ }^{*}$
}

\author{
Lucas Pizzolatto Konzen ${ }^{l}$ \\ Università degli Studi di Milano
}

O artigo discute a mudança do paradigma ecológico ao socioespacial na sociologia urbana, ocorrida nos países centrais do capitalismo ao longo das décadas de 1970 e 1980 . Os dois paradigmas são descritos em suas feições principais, ao que se segue uma análise específica das obras dos três autores que lideraram a mudança de paradigma: Henri Lefebvre, Manuel Castells e David Harvey. A análise referencia-se teoricamente na contribuição de Thomas Kuhn à sociologia do conhecimento.

Palavras-chave: Paradigma - Sociologia urbana - Henri Lefebvre - Manuel Caste1ls - David Harvey
This article discusses the paradigm shift from the ecological to the sociospatial paradigm in urban sociology that occurred in central capitalist countries during the 1970s and the 1980s. Both paradigms are described into their main features, to which follows a specific analysis of the work of three leading authors in the paradigm shift: Henri Lefebvre, Manuel Castells and David Harvey. The analysis is theoretically grounded on Thomas' Kuhn contribution to the sociology of knowledge.

Keywords: Paradigm - Urban sociology - Henri Lefebvre Manuel Castells - David Harvey

\section{Introdução}

A teoria dos paradigmas científicos, formulada por Thomas Kuhn (19221996), define o paradigma como sendo "aquilo que os membros de uma comunidade científica partilham" (KUHN, 1962; p. 221)2. As comunidades científicas, que existem em muitos níveis, são compostas pelos praticantes de

\footnotetext{
* The paradigm shift in urban sociology: from the ecological to the socio-spatial paradigm

${ }^{1}$ Doutorando em Direito e Sociedade, Programa R. Treves, Università degli Studi di Milano, Itália. Bolsista MIUR/UNIMI. Endereço para correspondências: Università degli Studi di Milano, Dipartimento di Scienze Giuridiche Cesare Beccaria Sezione di Filosofia e Sociologia del Diritto, Via Festa del Perdono, 7 - 20122 - Milano, Itália (lucas.pizzolatto@unimi.it).

2 A noção de paradigma, categoria-chave utilizada no livro de Kuhn, despertou bastante polêmica. Na primeira edição da obra, o termo era empregado com diversas acepções. Em posfácio à edição de 1969, Kuhn propõe que o termo paradigma seja usado tão-somente com duas acepções. O primeiro sentido, mais amplo, é sociológico: paradigma consiste em uma "constelação de crenças, valores, técnicas etc., partilhadas pelos membros de uma comunidade determinada" (KUHN, 1962; p. 220). A expressão matriz disciplinar também poderia ser usada para dar conta deste primeiro significado. O segundo sentido, mais restrito, refere-se às "soluções concretas de quebra-cabeças que, empregadas como modelos ou exemplos, podem substituir regras explícitas como base para a solução dos restantes quebra-cabeças da ciência normal" (KUHN, 1962; p. 220). Neste artigo, o termo paradigma será utilizado apenas na acepção de matriz disciplinar.
} 


\section{HUMANAS}

uma mesma especialidade, que se dedicam a um objeto de estudo próprio, produzindo e legitimando o conhecimento disciplinar. Seus membros submeteram-se a processos similares de socialização e treinamento profissional, durante os quais absorveram praticamente as mesmas lições e a mesma literatura-padrão cujas fronteiras confundem-se com as do objeto de estudo comunitário. Compartilham assim do consenso intersubjetivo em torno da validade de um determinado modelo de cientificidade. Em comum, possuem uma "constelação de compromissos de grupo" que permite estabelecer o que está dentro, à margem ou fora das fronteiras da normalidade científica (KUHN, 1962; pp. 222-28).

Os paradigmas mudam através dos tempos. Mudanças ocorrem quando "um paradigma mais antigo é total ou parcialmente substituído por um novo, incompatível com o anterior" (KUHN, 1962; p. 125). Em decorrência desse processo, podem igualmente se transformar as comunidades científicas, as ciências parciais e a própria noção global de ciência. As mudanças de paradigma, entretanto, não resultam de um desenvolvimento evolutivo e linear. Ao contrário, assemelham-se metaforicamente a revoluções ${ }^{3}$. Elas têm início na medida em que cresce em uma pequena parcela da comunidade científica o sentimento de que o paradigma vigente deixou de funcionar adequadamente. Esgotados os recursos da ciência normal para dar respostas a certos problemas que adquirem importância para alguns membros da comunidade científica em questão, estes passam a recorrer a elementos estranhos ao paradigma dominante. O paradigma entra em crise, ao mesmo tempo em que emergem constelações de compromissos alternativas e conflitantes disputando a adesão do grupo de cientistas. Transita-se de um período pré-paradigmático de competição entre escolas distintas de ciência revolucionária ${ }^{4}$ a um período pós-paradigmático de ciência normal, em que a escola que conquistou o domínio passa a ditar os novos fundamentos científicos do campo de saber (KUHN, 1962; pp. 125-228).

Referenciando-se teoricamente na contribuição de Kuhn à sociologia do conhecimento, este artigo estende o conceito de paradigma ao campo das ciências sociais ${ }^{5}$ para discutir a mudança de paradigma ocorrida na sociologia urbana ao longo das décadas de 1970 e 1980, enfocando especificamente a maneira pela qual ela se deu no contexto do capitalismo central - Estados Unidos da América (EUA) e países da Europa Ocidental. Neste período, ocorreu a passagem do paradigma ecológico ao paradigma socioespacial na sociologia urbana.

\footnotetext{
${ }^{3}$ Kuhn denomina as mudanças de paradigma de "revoluções científicas", em analogia proposital com as revoluções políticas. No entanto, esclarece que as revoluções científicas ocorrem muitas vezes em pequena escala e não necessariamente parecem revolucionárias para quem está fora da comunidade científica atingida.

4 "Há escolas nas ciências, isto é, comunidades que abordam o mesmo objeto científico a partir de pontos de vista incompatíveis" (KUHN, 1962; p. 223).

${ }^{5} \mathrm{O}$ livro de Kuhn está repleto de ilustrações concretas de casos em que ocorreram mudanças de paradigma nas ciências, embora se atenha àquelas transcorridas em disciplinas do âmbito das chamadas "ciências naturais".
} 


\section{A mudança de paradigma em Sociologia Urbana: do paradigma ecológico ao socioespacial}

Não por acaso, à época o novo paradigma foi rotulado de "nova sociologia urbana" ou ainda de "perspectiva crítica em sociologia urbana", em claro contraste com o paradigma dominante anteriormente ${ }^{6}$. A primeira seção descreve o paradigma ecológico em suas feições principais, ao passo que a seção seguinte examina os aspectos centrais do paradigma socioespacial. Na terceira seção, realiza-se uma breve análise das obras dos três autores que lideraram a mudança de paradigma: Henri Lefebvre, Manuel Castells e David Harvey.

\section{O paradigma ecológico}

O paradigma ecológico está vinculado à fundação da sociologia urbana enquanto disciplina científica, assim como à Escola de Chicago, movimento intelectual responsável por lhe erigir em princípios do século passado. Por esta expressão tornou-se popularmente conhecido o conjunto de trabalhos de pesquisa conduzidos entre 1915 e 1940 por professores e estudantes da Universidade de Chicago, berço da sociologia estadunidense ${ }^{7}$, cujo objeto e campo empírico de investigações correspondiam à própria cidade de $\mathrm{Chicago}^{8}$, transformada em uma espécie de laboratório. Costuma-se associar à Escola de Chicago uma ampla gama de autores, entre os quais se destacam em importância Robert Park (1864-1944), Ernest Burgess (1886-1966), Roderick McKenzie (1885-1940) e Louis Wirth (1897-1952). A despeito da heterogeneidade de suas contribuições teóricas e empíricas particulares,

${ }^{6}$ Para as primeiras análises da mudança de paradigma em sociologia urbana a partir de distintas perspectivas, ver Zukin (1980), Jaret (1983), Hawley (1984), Gottdiener e Feagin (1988) e Walton (1993).

${ }^{7}$ Fundada em 1890, desde o princípio a Universidade de Chicago voltou seu foco à pesquisa e à pósgraduação, reunindo muitos professores-pesquisadores em tempo pleno, para quem a atividade de ensino assumia caráter secundário. Supunha-se que apenas aqueles que conduziam pesquisas estariam aptos a treinar os estudantes para fazer o mesmo. Ademais, também passou a funcionar na instituição desde muito cedo uma editora universitária, destinada a difundir os resultados das investigações realizadas. O Departamento de Sociologia, estabelecido em 1892, desempenhou papel pioneiro na consolidação dos estudos sociológicos nos EUA, destacadamente por intermédio do American Journal of Sociology (publicada desde 1895, foi uma das primeiras revistas científicas sociológicas do mundo, ao lado da L'Année Sociologique, lançada por Durkheim na França quase que concomitantemente) e da liderança exercida junto à American Sociological Society (nascida em 1905, hoje American Sociological Association).

${ }^{8}$ A Chicago de princípios do século XX era marcada pelo astronômico crescimento populacional. Contados em torno de 5.000 habitantes no censo de 1840 , a cidade norte-americana superaria a marca de um milhão de residentes em 1890 e sua população alcançaria a cifra de $3.500 .000 \mathrm{em}$ 1930. Desenvolvendo-se enquanto um dos mais importantes centros industriais, comerciais e financeiros dos EUA, a cidade atraía um fluxo enorme de pessoas, alimentado em parte pelo êxodo rural, em parte pela chegada de imigrantes estrangeiros, sobretudo europeus. Se as outrora pacatas ruas da cidade se transformavam na medida em que nelas se edificavam modernos arranha-céus de aço e concreto, ela também conhecia uma intensa ebulição cultural e inéditos protestos de rua e greves de operários. 


\section{HUMANAS}

a produção científica desse grupo precursor de sociólogos urbanos guarda características em comum para além da inserção acadêmica e do contexto empírico que permitem lhes atribuir indisfarçável unidade de pensamento e, por conseguinte, o rótulo de escola (COULON, 1992; GRAFMEYER \& JOSEPH, 1990).

Essas características transparecem nos artigos de Park, Burgess, McKenzie e Wirth reunidos no livro The City, tido não só como o manifesto da Escola de Chicago, mas também como a obra fundamental do paradigma ecológico ${ }^{9}$. Ao centro das preocupações compartilhadas pelos autores está a questão da coesão social na cidade moderna. Ao invés dos aportes de pensadores como Karl Marx (1818-1883), Friedrich Engels (1820-1895) ou Max Weber (1864-1920), a herança teórica que repercutiu na escolha dos problemas de pesquisa sobre os quais eles se debruçariam e no arsenal conceitual a partir dos quais estes seriam abordados foi notadamente a de Georg Simmel $(1858-1918)^{10}$ e Émile Durkheim $(1858-1917)^{11}$. Disso resulta a ênfase conferida ao conceito de desorganização social, que retrata o declínio da influência exercida sobre os indivíduos por parte do conjunto de convenções, regras e valores coletivos de uma dada sociedade. O risco de declínio da organização social surgiria sempre que transcorressem mudanças repentinas e profundas, a exemplo de um súbito adensamento urbano ou de uma crise política.

${ }^{9} \mathrm{O}$ livro privilegia temas como a integração dos imigrantes, a distribuição dos grupos sociais no tecido urbano e o comportamento de indivíduos marginais na cidade. O conhecido estudo de Burgess (1925) desenvolve um modelo ecológico de estruturação urbana, segundo o qual as cidades se articulariam ao redor de cinco zonas territoriais concêntricas. Park (1925) se interessa, por exemplo, pela figura marginal do hobo, o trabalhador eventual que migra de uma cidade a outra ou simplesmente o sem-teto que faz trabalhos esporádicos.

${ }^{10}$ Ao observar as transformações da Europa de seu tempo, marcada pela industrialização e pela urbanização galopantes, Simmel veicula uma visão pessimista da grande metrópole. A ela estariam atrelados traços culturais peculiares, o que implicaria a existência de uma cultura urbana, capaz de modelar e uniformizar os modos de vida e a personalidade de seus habitantes. Se a cidade, por um lado, alargaria a vida social do individuo ao multiplicar as possibilidades de interação, por outro lado ela tornaria impessoal a convivência do indivíduo com seus pares. Essa contradição decorreria da dissolução dos fortes laços afetivos que uniam os membros das pequenas comunidades, os quais, com a urbanização, teriam cedido espaço a um viver urbano conformado por instituições, regras e valores impessoais. Para o autor, a figura do estrangeiro personifica aqueles que ao mesmo tempo estão fisicamente próximos e culturalmente distantes da sociedade em que buscam se inserir, sujeitando-se à tensão cotidiana de precisar ajustar sua própria individualidade às estruturas de um mundo que permanece exterior. Cf. Simmel (1950a; 1950b).

11 Para Durkheim, o indivíduo é em larga medida um ser socialmente determinado. Na sociedade moderna, essas forças sociais seriam representadas tanto pela consciência coletiva - o conjunto de ideias, valores, sentimentos e crenças que as pessoas internalizaram - quanto pela complexa divisão social do trabalho e a solidariedade orgânica por esta desencadeada - cada indivíduo desempenharia uma tarefa altamente diferenciada, restando extremamente dependente dos outros para viver. Se o comportamento individual se conformaria de certo modo pela personalidade que distingue cada um, em grau imensamente maior seria moldado pela consciência coletiva de uma sociedade e pelos laços de solidariedade. No entanto, a coesão social e as forças sociais que a mantém correriam o risco de ser eventualmente corroídas em decorrência dos bruscos processos de mudança social característi$\cos$ da modernidade, conduzindo a situações temporárias de anomia. O conceito remete à carência de mecanismos eficazes de regulação social, situação que poderia gerar dificuldades aos indivíduos para compreender seus papéis sociais. Cf. Durkheim $(1893 ; 1897)$. 


\section{A mudança de paradigma em Sociologia Urbana: do paradigma ecológico ao socioespacial}

Ao estado temporário de desorganização sucederia a reorganização da sociedade, sob bases distintas das outrora vigentes.

A característica mais saliente da Escola de Chicago, entretanto, é aquela que inspirou a denominação do paradigma ao qual se vincula: sua visão ecológica do comportamento humano na cidade ${ }^{12}$. Ocorre que para os sociólogos dessa tradição, influenciados pelo darwinismo social, a cidade se define enquanto uma ordem natural, à semelhança dos ambientes de que trata a biologia. Assim, seria possível estudar em termos de distribuição, acomodação, competição, seleção e simbiose - analogamente às relações entre animais ou plantas na natureza - as relações entre os seres humanos na cidade, na medida em as forças do meio afetariam a organização das comunidades humanas. A diferença estaria no fato de que os seres humanos, ao contrário dos animais e das plantas, têm a capacidade de selecionar o seu habitat e adaptá-lo às suas necessidades $^{13}$. Esses aspectos explicam a preocupação com a morfologia da cidade de Chicago, a localização espacial precisa das diferentes comunidades e a identificação dos modelos culturais e morais seguidos por cada uma.

Os sociólogos urbanos de Chicago acreditavam na capacidade da sociedade em que viviam de superar os problemas sociais que supunham ser decorrentes de uma situação temporária de desorganização social, desencadeada por mudanças bruscas como o crescimento urbano acelerado, as inovações tecnológicas e a intensa chegada de migrantes. A reorganização social levaria à assimilação das minorias étnicas e dos grupos marginais, bem como à aculturação daqueles cujas atitudes individuais destoavam dos valores sociais predominantes. Neste sentido, estudar cientificamente as desordens sociais concretas confrontadas por Chicago, mas também compartilhadas por outras cidades estadunidenses, permitiria produzir conhecimentos úteis ao seu enfrentamento. A sociologia urbana nasce, portanto, voltando-se para uma tarefa que, longe de se revelar especulativa, envolvia a compreensão empiricamente fundada da sociedade ${ }^{14} \mathrm{e}$, a partir disso, a ação inclinada à promoção de reformas destinadas a promover a inclusão dos indivíduos considerados mais fracos, em que pese comprometida com a manutenção das estruturas sociais.

\footnotetext{
${ }^{12}$ Cabe ressaltar que a ecologia urbana da Escola de Chicago pouco tem a ver com o que se conhece contemporaneamente por tal expressão, mais vinculada à ecologia política e à preocupação com a sustentabilidade ambiental dos ecossistemas urbanizados.

${ }^{13}$ Ver, por exemplo, o artigo de McKenzie (1925).

${ }^{14} \mathrm{O}$ empiricismo da Escola de Chicago levou a inovações importantes nos estudos sociológicos, sobretudo no que se refere à metodologia empregada. Os métodos utilizados no trabalho de campo eram bastante diversificados, priorizando o qualitativo. Entre as técnicas de investigação usadas pode-se mencionar a análise de documentos pessoais, a entrevista, a observação direta ou participante e a reconstrução de histórias de vida. Park, o fundador da Escola, que ingressara na universidade após uma carreira como repórter, dizia que o trabalho de sociólogo era necessário para compreender o que se lê nos jornais. Para ele, o sociólogo era uma espécie de super-repórter, cujos métodos condiziam com uma forma superior de jornalismo ocupada das tendências de longo prazo antes que da superfície das coisas.
} 


\section{HUMANAS}

\section{Quadro 1}

Paradigma ecológico em sociologia urbana, quadro elaborado com base em Gottdiener e Feagin (1988).

\begin{tabular}{|c|c|}
\hline CONCEITOS & $\begin{array}{l}\text { (a) A unidade de análise é o indivíduo, ou então a firma } \\
\text { individualmente considerada (no mercado, por exemplo); } \\
\text { (b) o conceito de comunidade é integrado pela noção de } \\
\text { diferenciação funcional dos indivíduos que compõem uma } \\
\text { população em um esquema de divisão social do trabalho; } \\
\text { (c) o desenvolvimento social ocorre por meio da adaptação da } \\
\text { comunidade às mudanças no ambiente, as quais ocorrem em razão } \\
\text { de inovações tecnológicas; } \\
\text { (d) os indivíduos competem entre si e os mais adaptados, aqueles } \\
\text { de maior importância funcional na divisão do trabalho, assumem } \\
\text { o controle dos recursos socioespaciais. }\end{array}$ \\
\hline QUESTÕES & $\begin{array}{l}\text { (a) Qual é o peso dos fatores ecológicos no desenvolvimento urbano? } \\
\text { (b) Qual é a natureza da organização sociofuncional que se } \\
\text { desenvolve à medida que as populações humanas se adaptam ao } \\
\text { ambiente urbano } \\
\text { (c) Como o crescimento e o declínio populacional afetam a } \\
\text { organização sociofuncional? } \\
\text { (d) Quais são as consequências das novas tecnologias de } \\
\text { transporte e comunicação na organização sociofuncional? }\end{array}$ \\
\hline TEORIAS & $\begin{array}{l}\text { (a) As mudanças sociais têm origem externa à comunidade, esta } \\
\text { se reorganiza em face das perturbações no ambiente; } \\
\text { (b) o desenvolvimento social é um processo de busca do } \\
\text { equilíbrio que contrabalanceia população, organização social, } \\
\text { ambiente e tecnologia disponível; } \\
\text { (c) novos desenvolvimentos decorrem da introdução de inovações } \\
\text { tecnológicas, principalmente em transportes e comunicação; } \\
\text { (d) a adaptação ao ambiente ocorre mediante diferenciação } \\
\text { funcional na comunidade. }\end{array}$ \\
\hline SUPOSIÇÕES & $\begin{array}{l}\text { (a) O desenvolvimento social busca o equilíbrio e ocorre mediante } \\
\text { adaptação e seleção funcional dos mais aptos em face ao ambiente; } \\
\text { (b) a interação social nos sistemas capitalistas é assumida como } \\
\text { estável e as mudanças provêm de fora; } \\
\text { (c) a organização social no sistema capitalista opera através da } \\
\text { interdependência funcional e não, por exemplo, por meio do } \\
\text { poder, da desigualdade e da ação estatal; } \\
\text { (d) a organização funcional consiste de indivíduos e unidades } \\
\text { organizacionais que podem ser individualmente consideradas } \\
\text { (individualismo metodológico). }\end{array}$ \\
\hline
\end{tabular}

O programa de pesquisa direcionado à ação reformista fez com que o conhecimento sociológico produzido e validado com base nas noções de ecologia humana desenvolvidas pela Escola de Chicago de fato desempenhasse um papel relevante na formulação das políticas urbanas nos EUA. 


\section{A mudança de paradigma em Sociologia Urbana: do paradigma ecológico ao socioespacial}

Conforme demonstra Kuklick (1980), a visão de cidade própria ao paradigma ecológico não se restringiu aos cientistas sociais, também alcançando o corpo de profissionais da burocracia estatal responsável pelo planejamento urbano, para quem as noções ecológicas se revelaram condizentes com suas obrigações ocupacionais. A sociologia urbana oferecia-lhes bases científicas, supostamente neutras e imparciais quanto a valores e interesses, que legitimavam o direcionamento da atenção no que tange às intervenções urbanísticas aos anseios da elite da população. Cabia às agências estatais, por meio de uma administração técnica, remediar e controlar os problemas urbanos, os quais eram reduzidos a meras doenças sociais vinculadas à desorganização social.

Embora se mostre correto associar as características expostas à Escola de Chicago ${ }^{15}$, elas sem dúvida ultrapassaram os confins daquele círculo de pesquisadores. As teorias confiáveis, o conjunto de conceitos básicos, as suposições tácitas e as questões privilegiadas nas pesquisas que tiveram origem nesses trabalhos pioneiros, uma vez disseminadas e transferidas a outros contextos, foram reformuladas e assumiram novos contornos ao conformarem, em maior ou menor grau, o pensamento da comunidade científica de sociólogos urbanos que se constituiria em torno do paradigma ecológico. As principais feições deste paradigma são descritas no Quadro 1.

\section{O paradigma socioespacial}

Até o momento em que tiveram início as radicais rupturas epistemológicas das décadas de 1970 e 1980, o paradigma ecológico fazia-se sinônimo de sociologia urbana. Contudo, os eventos transcorridos neste período evidenciaram a crise de um modelo de cientificidade a serviço do urbanismo moderno, que se tornara incapaz de oferecer respostas teóricas aos desafios postos por uma era de pobreza urbana, profunda segregação social e racial, intensa mobilização comunitária, demandas coletivas pelo direito à moradia $\mathrm{e}$ agitação político-social nas ruas de diversas metrópoles do planeta. Para muitos pensadores parecia cada vez mais claro que o urbanismo moderno, antes que uma solução para os males de um supostamente caótico fenômeno natural de urbanização, era parte integrante dos problemas que prometia combater ${ }^{16}$. A naturalização das lógicas urbanas operada pelo paradigma ecológico enquanto teoria do status quo não se destinaria a desligá-las da política, a ocultar as relações de poder no espaço urbano e a disfarçar as relações sociais conflituosas e os processos históricos que presidem o desenvolvimento das cidades?

\footnotetext{
${ }^{15}$ Nos anos 1960 surgiu na mesma Universidade de Chicago uma "Nova Escola de Chicago" ou "Segunda Escola de Chicago", voltada ao estudo do desvio social e à criminologia, cujas características são diversas daquela aqui tratada.

${ }^{16}$ No campo do urbanismo, o estudo de Jacobs (1961) foi uma das obras que rompeu com as bases da disciplina e com as práticas correntes de planejamento urbano.
} 


\section{HUMANAS}

Era isso o que começavam a indagar diversos autores, para quem era preciso erigir uma ciência crítica do urbanismo moderno e das ideologias sobre a cidade (STÉBÉ \& MARCHAL, 2007; pp. 28-29).

Nesse rumo, a herança teórica marxista, marginalizada pela Escola de Chicago, foi aquela da qual provieram os principais fundamentos para a construção de um paradigma alternativo em sociologia urbana. Escrevendo no contexto da revolução industrial, Marx e Engels desenvolveram uma compreensão crítica acerca do capitalismo como sistema global de organização social e erigiram uma teoria para explicar seu funcionamento. Tal abordagem ofereceu as bases para as perspectivas do conflito em sociologia, as quais enfatizam o conflito entre grupos com interesses opostos como um aspecto que historicamente permeia as sociedades. A perspectiva do conflito considera a importância do modo por meio do qual os humanos organizam a sua produção e reprodução material na conformação da vida cotidiana. Lutas sociais em um mundo material são vislumbradas como a causa maior da mudança social. Disso decorre a possibilidade de sua promoção consciente por parte dos grupos sociais interessados na transformação do sistema.

No entanto, tanto nos escritos de Marx e Engels quanto de modo mais geral nas teorias do conflito então disponíveis verificava-se a ausência de reflexões específicas e profundas sobre as questões urbanas nas sociedades capitalistas (LEFEBVRE, 1972). As obras fundadoras analisavam apenas brevemente temas como condições de vida urbana, habitação e propriedade privada (ENGELS, 1845; 1872). Ademais, cabia reconhecer - e assim o fizeram os pioneiros do paradigma socioespacial em sociologia urbana - que a transferência sem sérias modificações dos argumentos marxistas do século XIX para a realidade contemporânea era altamente problemática (TUCKER \& TUCKER JR., 2001; p. 82). Se a perspectiva do conflito se prometia produtiva para analisar as questões urbanas contemporâneas, era necessário recepcioná-la criticamente e desenvolvê-la de modo inovador para torná-la um referencial teórico apropriado ao enfrentamento das problemáticas urbanas então emergentes.

Foi nesta esteira que, a partir dos fins da década de 1960, a perspectiva do conflito aplicada aos estudos urbanos finalmente apareceu com força na Europa, vinculada ao que se tornou conhecido por Escola Neomarxista de sociologia urbana. $\mathrm{O}$ nome precursor do novo paradigma socioespacial em formação foi o filósofo e sociólogo francês Henri Lefebvre (1901-91) ${ }^{17}$,

\footnotetext{
17 "Lefebvre deve ser colocado na frente da fila, pois foi ele quem primeiramente mostrou ao Marxismo o caminha de volta à cidade. Nos primórdios dos anos 1970, [...] apenas ele havia quebrado o silêncio do Marxismo sobre a cidade" (KATZNELSON, 1992; p. 93, tradução do autor). "Manuel Castells e David Harvey, ambos frequentemente apontados pelos urbanistas como os pensadores seminais do novo urbanismo, possuem um imenso, inconfesso débito para com Lefebvre. Este, ao escrever uma série de seis livros sobre urbanismo principiando em 1968, merece o título de progenitor" (GOTTDIENER, 1993; p. 130, tradução do autor).
} 
cujas idéias vinculavam-se ao movimento estudantil de Maio de $1968^{18}$. Outra importante referência para a construção de uma abordagem do conflito na disciplina foi o sociólogo espanhol Manuel Castells ${ }^{19}$, enquanto o geógrafo britânico David Harvey indubitavelmente consiste em um terceiro autor significativo $^{20}$. Se de um lado eles provocativamente denunciaram os contornos ideológicos dos estudos urbanos existentes até aquele tempo - por vezes inclusive negando-lhes qualquer caráter científico -, de outro Lefebvre, Castells e Harvey também contribuíram para desconstruir radicalmente os conceitos então vigentes ao substituí-los por outros inteiramente novos.

Embora suas construções teóricas apresentem distintas particularidades e orientações ${ }^{21}$, Lefebvre, Castells e Harvey compartilham de um acordo de princípio. Tendo em comum a inspiração marxista, os três autores direcionam sua atenção aos conflitos sociais no espaço urbano e às relações entre capitalismo e urbanização. Argumentam que as lutas sociais estão ao centro do processo de transformação espacial. Portanto, os espaços não são neutros e não existem a priori, mas refletem e modelam a vida social. O espaço não se caracteriza simplesmente por ser um espelho das relações sociais; mais do que isso, ele é também uma fonte de dinâmicas sociais. O espaço representa tanto uma maneira pela qual o passado alcança o presente quanto um modo pelo qual o presente fornece material para construir o futuro. Sem entender a sociedade como um todo, não é possível entender o espaço. Uma teoria do espaço, por conseguinte, consiste em um elemento essencial de uma teoria social abrangente e vice-versa. Com base na premissa da espacialidade das relações sociais forma-se o paradigma socioespacial em sociologia urbana, em torno do qual se aglutinaria toda uma comunidade de cientistas sociais ${ }^{22}$. As feições mais relevantes do paradigma são sintetizadas no Quadro 2.

\section{Lefebvre, Castells, Harvey}

Lefebvre é um dos mais influentes teóricos do paradigma socioespacial em sociologia urbana. Em meio à rica discussão iniciada pelo autor sobre a urbanização da sociedade (LEFEBVRE, 1970a; 1970b), assume especial relevância, entre os conceitos por ele cunhados, a noção de direito à cidade (LEFEBVRE, 1968).

\footnotetext{
${ }_{18}$ Para uma análise da obra e biografia de Lefebvre, consultar Hess (1988).

${ }_{19}$ Para uma análise completa e atualizada da obra de Castells, ver Stalder (2006).

${ }^{20}$ Análises panorâmicas dos principais autores engajados em uma abordagem do conflito nos estudos urbanos destacam o papel de Lefebvre, Castells e Harvey. Ver Katznelson (1992) e Merrifield (2002).

${ }^{21}$ Para debates sobre o assunto, consultar Gottdiener (1985), Katznelson (1992) e Merrifield (2002).

22 A definição pelo rótulo de sociologia urbana do próprio campo de saber pautado pelo paradigma socioespacial assume um caráter meramente convencional ao aludir em realidade ao movimento de sociólogos, geógrafos, economistas, historiadores etc. que ultrapassam os limites tradicionais de suas disciplinas para discutir o espaço urbano e a cidade como objeto comum (AZUELA, 1999; p. 178).
} 


\section{HUMANAS}

\section{Quadro 2}

Paradigma socioespacial em sociologia urbana, quadro elaborado com base em Gottdiener e Feagin (1988).

\begin{tabular}{|c|c|}
\hline CONCEITOS & $\begin{array}{l}\text { (a) As sociedades são especificadas de acordo com o seu modo de } \\
\text { produção e reprodução. São formas de organização compostas por } \\
\text { classes, relações de propriedade, estado e modos de regulação; } \\
\text { (b) nas sociedades contemporâneas, o processo de acumulação de } \\
\text { capital e a exploração da força de trabalho são centrais ao } \\
\text { desenvolvimento social; } \\
\text { (c) as relações entre os processos de produção e reprodução } \\
\text { capitalistas e o espaço são intrínsecas ao desenvolvimento social; } \\
\text { (d) os bens imóveis e as infraestruturas urbanas constituem um } \\
\text { segundo circuito do capital que torna mais complexo o } \\
\text { entendimento do capitalismo. }\end{array}$ \\
\hline QUESTÕES & $\begin{array}{l}\text { (a) Quais são os atributos do poder e da desigualdade na cidade e } \\
\text { como estes se relacionam como os padrões espaciais de } \\
\text { desenvolvimento urbano? } \\
\text { (b) De que formas os processos produtivos e reprodutivos de } \\
\text { acumulação de capital se manifestam na organização socioespacial? } \\
\text { (c) Qual é a natureza da complexa articulação entre capital, } \\
\text { trabalho, estado e assentamentos urbanos? } \\
\text { (d) Quais são as relações entre estrutura e agência, determinismo e } \\
\text { contingência, presente, passado e futuro, nos processos de } \\
\text { mudança social? }\end{array}$ \\
\hline TEORIAS & $\begin{array}{l}\text { (a) A circulação do capital, ao invés da produção, explica } \\
\text { importantes aspectos da urbanização, incluindo a organização } \\
\text { capitalista, a reprodução da força de trabalho e as políticas urbanas; } \\
\text { (b) mudanças no desenvolvimento urbano podem ser explicadas pela } \\
\text { reprodução da força de trabalho juntamente à provisão pelo estado } \\
\text { de valores de uso e pelas as inter-relações entre capital e estado; } \\
\text { (c) o desenvolvimento urbano é uma manifestação do choque entre a } \\
\text { lógica da acumulação do capital e as demandas dos trabalhadores; } \\
\text { (d) as relações socioespaciais são decorrentes das demandas de } \\
\text { acumulação do capital e ao mesmo tempo o reflexo das relações } \\
\text { que permeiam a produtivo. }\end{array}$ \\
\hline SUPOSIÇÕES & $\begin{array}{l}\text { (a) A interação social é dominada por relações sociais antagônicas, } \\
\text { já que a sociedade é uma organização estratificada e caracterizada } \\
\text { por contradições e padrões de desenvolvimento desiguais; } \\
\text { (b) em sociedades antagônicas, o desenvolvimento social é } \\
\text { instável. As contradições do crescimento e o desigual } \\
\text { desenvolvimento alimentam atividades políticas que podem } \\
\text { desencadear mudanças; } \\
\text { (c) nenhuma sociedade pode ser adequadamente analisada sem se } \\
\text { fazer referência ao seu contexto global e a sua trajetória histórica; } \\
\text { (d) o individualismo metodológico é superado por meio da } \\
\text { especificação das relações entre estrutura e agência e da consideração } \\
\text { dos conflitos entre unidades coletivas como classes e grupos. }\end{array}$ \\
\hline
\end{tabular}




\section{A mudança de paradigma em Sociologia Urbana: do paradigma ecológico ao socioespacial}

Por intermédio da proposição de um novo direito humano, o autor sintetiza todo um programa, o qual intenciona inserir questões sociais concernentes à cidade e à vida urbana como prioridade na agenda política - em outras palavras, politizar o espaço urbano, visualizado até aquele momento mais como um assunto técnico sob competência dos profissionais do urbanismo. De acordo com Lefebvre, a falta de consciência acerca das políticas do espaço revela a alienação da vida cotidiana. De todo modo, o programa político do direito à cidade encontra-se ainda em gestação em uma escala global, está longe de ser concluído precisamente porque "ele não é um direito natural nem um direito contratual" (LEFEBVRE, 1973; p. 21, tradução do autor), é um direito em construção e a ser construído.

Por esse motivo, Lefebvre evita qualquer tentativa de oferecer uma definição abrangente e fechada do conteúdo desse direito, preferindo, ao invés disso, fornecer algumas pistas e indicações de seu significado em nível um tanto abstrato. Por exemplo, ele afirma que o direito à cidade é negado às classes, grupos e indivíduos impedidos de participar plenamente da apropriação coletiva do espaço. Mas o que significa exatamente se apropriar do espaço urbano? Primeiramente, o autor refere-se ao direito à moradia adequada, ao direito a um espaço de habitação e intimidade na cidade de que é titular todo aquele que nela vive. Mas outros elementos correlacionados parecem ser igualmente relevantes. Nesse sentido, apropriação para Lefebvre também significa o direito de ser cidadão para além de mero morador, o que implica o desenvolvimento de uma concepção de cidadania urbana que contemple a ampla participação da população na gestão da cidade. Adicionalmente, a apropriação da cidade envolve o direito de tomar parte nos circuitos de comunicação, informação e troca próprios à vida urbana, os quais dependem dos espaços públicos (LEFEBVRE, 1968).

Todavia, a dúvida concernente à maneira segundo a qual a apropriação do espaço urbano de fato ocorre nas sociedades capitalistas permaneceria praticamente carente de resposta adequada sem a sofisticada teoria da produção do espaço de Lefebvre (1974). Ele sustenta que o espaço urbano sempre é o resultado de um processo social de produção. Assim, o espaço constantemente está sendo reconstruído como um conjunto de relações sociais, as quais podem predominantemente assumir o sentido de produto ou de obra de arte (oeuvre). O que diferencia o produto da obra é o balanço de qualidades apresentado pelo espaço urbano socialmente produzido. Por um lado, se o espaço encoraja valores de uso, tais como o encontro, a centralidade, a reunião e a convergência de diferenças, então ele propicia condições para o florescimento de comunidades humanas criativas e revela-se a si mesmo como obra na acepção forte de obra de arte. Por outro, se o espaço prioriza valores de troca, enquanto mercadoria medida pela sua exclusividade, cujos valores de uso tornam-se intercambiáveis por dinheiro (consequentemente um instrumento para a acumulação de capital), então ele se reduz a um mero produto. 


\section{HUMANAS}

O balanço de qualidades, por conseguinte, constitui o resultado do processo produtivo. Ocorre que a produção capitalista do espaço tem historicamente resultado em um desequilíbrio de qualidades, uma vez que confere ênfase excessiva aos valores de troca em detrimento dos valores de uso. Nesse sentido, a luta social pelo direito à cidade é um desafio à dominação da obra pelo produto.

"Um grupo, uma classe ou uma fração de classe não constitui a si mesmo e nem se reconhece enquanto sujeito coletivo senão por meio da produção de um espaço" (LEFEBVRE, 1974; p. 478, tradução do autor). Apoiado nessa ideia, Lefebvre vê a transformação do espaço em mercadoria como uma estratégia empregada por sujeitos coletivos hegemônicos no interior das sociedades capitalistas com a finalidade de dominar o espaço para seus propósitos particulares. É que, uma vez produzido, o espaço torna-se algo que vai além de um mero produto. Ele interfere com o próprio processo produtivo, tornando-se, ao mesmo tempo, produto e produtor, portanto um instrumento de hegemonia ${ }^{23}$ apto a ser usado para atingir múltiplas metas e interesses. Por exemplo, o espaço da cidade é estrategicamente manejado visando segregar espacialmente diferentes classes sociais e grupos ${ }^{24}$. Contudo, estratégias hegemônicas de produção espacial enfrentam resistência contra-hegemônica, na medida em que estratégias de apropriação do espaço são também desenvolvidas por atores coletivos não-hegemônicos. Destarte, qualquer processo de produção espacial é permeado pela luta social (LEFEBVRE, 1974).

Enquanto sistema global de organização social e econômica marcado pela diversidade em sua unidade, o capitalismo tende a produzir um espaço urbano homogêneo, chamado por Lefebvre de espaço abstrato. Ele se refere ao espaço globalizado dos aeroportos, estações de trem, vias expressas, prédios de escritórios, lojas de grife, shopping centers e assim por diante. Na contemporaneidade, diante do silêncio e da passividade dos usuários da cidade, os quais vêem os espaços de sua vida cotidiana manipulados, os agentes coletivos hegemônicos estão tomando a iniciativa de espalhar por toda parte seus produtos espaciais, comprando e vendendo espaços repetitivos, tal qual fazem com qualquer outra mercadoria. A despeito disso, Lefebvre argumenta que por meio da luta social é possível impor resistência e acentuar as diferenças que fazem qualquer obra espacial se tornar peculiar, única e insubstituível como conjunto de relações sociais.

\footnotetext{
23 "O conceito de hegemonia introduzido por Gramsci [...] indica muito mais que uma influência, e mais inclusive que o uso perpétuo da violência repressiva. A hegemonia é exercida perante toda a sociedade, cultura e conhecimento aí abrangidos [...]. Ela é, por conseguinte, exercida sobre as instituições e sobre as representações. Hoje em dia a classe dominante mantém a sua hegemonia por todos os meios possíveis, incluindo o conhecimento. $\mathrm{O}$ vínculo entre conhecimento e poder tornase manifesto" (LEFEBVRE, 1974; pp. 17-18, tradução do autor).

${ }^{24}$ A segregação não é o resultado de um desenvolvimento inevitável, evolucionário ou natural. Ao contrário, ela é estrategicamente gerada, seja pela realocação e confinamento forçado de certos grupos em guetos através de ações estatais deliberadas, seja por processos dirigidos pelo mercado (especulação fundiária, altos custos da habitação).
} 


\section{A mudança de paradigma em Sociologia Urbana: do paradigma ecológico ao socioespacial}

Cedo ou tarde, entretanto, se as forças contra-hegemônicas não passam da resistência ao contra-ataque, a pujança homogeneizante absorve, integra e elimina as diferenças (LEFEBVRE, 1974).

Lefebvre considera a cidade um espaço social ocupado e modelado como resultado de lutas sociais passadas, as quais envolveram práticas espaciais (presenças, ações e discursos) de distintos grupos em conflito. A espacialidade preexistente tende a encorajar ou proibir práticas espaciais, de acordo com as representações do espaço construídas pelos grupos que conquistaram hegemonia social, doravante dominando o espaço através do controle de seu processo de produção. Os grupos não-hegemônicos buscam desafiar as representações do espaço por meio de sua própria prática espacial. Neste processo de resistência, eles constroem espaços de representação almejando participar do processo produtivo e apropriar espaço para suas próprias demandas e necessidades. Desta maneira, contraespaços funcionam como fontes de mudança socioespacial (LEFEBVRE, 1974).

Quando os cidadãos se insurgem contra a construção de uma via expressa, quando eles demandam ao governo equipamentos urbanos, lugares para jogar e se encontrar, é possível perceber como contraespaços, contraplanos e contraprojetos (espaços de representação) aos impostos de cima para baixo (representações do espaço) são introduzidos na realidade espacial. Para Lefebvre, apenas a pressão social de baixo para cima baseada em presenças, ações e discursos no espaço (prática espacial) é capaz de modificar a distribuição dos recursos destinados aos interesses coletivos. Porém, a pressão social não deve ser direcionada apenas ao Estado como administrador dos interesses gerais da sociedade. Ela pode e deve também confrontar o Estado, o qual é simultaneamente responsável pela gestão dos interesses das classes e grupos sociais. Servindo de esquema analítico do processo de produção espacial, emerge da teoria de Lefebvre uma tríade conceitual: representações do espaço, espaços de representação e prática espacial (Quadro 3). Qualquer uma dessas três categorias operacionais interfere diferentemente no processo de produção social do espaço, ao mesmo tempo em que as ligações entre elas são extremamente importantes (LEFEBVRE, 1974).

Também no pensamento de Castells a problemática da produção do espaço urbano assume um lugar central. No capitalismo avançado, argumenta o autor, os sistemas urbanos constituem parte da estrutura social. A cidade constitui mais precisamente um espaço de reprodução social e de consumo coletivo antes que um espaço de produção. A questão urbana é representada pelos conflitos que emergem da organização dos meios de consumo coletivo na vida cotidiana dos grupos sociais: moradia, educação, saúde, cultura, transporte e assim sucessivamente. As empresas capitalistas não satisfazem integralmente essas demandas para todos os habitantes, principalmente porque oferecer os bens e serviços requeridos não se mostra suficientemente lucrativo. 


\section{HUMANAS}

A fim de aliviar essa contradição, o Estado, sob a pressão de sindicatos, partidos políticos de esquerda e movimentos populares, começa a prover diretamente tais bens e serviços (os governos constroem infraestrutura de transportes, financiam grandiosos complexos habitacionais, organizam hospitais e escolas). Essas intervenções, todavia, direcionam-se a problemas que são em verdade componentes estruturais do capitalismo avançado. Há limites para o crescimento da intervenção estatal, na medida em que tributos cada vez mais elevados se revelam necessários para financiar o consumo coletivo. Em consequência, as intervenções do Estado apenas deslocam as contradições do campo da economia para o campo da política (CASTELLS, 1972).

\section{Quadro3}

Categorias da teoria da produção do espaço, quadro elaborado pelo autor com base em Lefebvre (1974).

ESPAÇOS DE REPRESENTAÇÃO: os espaços vivenciados (espace vécu). É o espaço dominado em uma sociedade, portanto consiste em um subespaço ou contraespaço. Esta categoria faz referência aos complexos e diversificados simbolismos individuais e coletivos, os quais tendem a constituir um sistema mais ou menos incoerente de signos e códigos não-verbais. Nisso se incluem imagens, memórias, desejos e sonhos em relação ao espaço, sejam concretamente experimentados, sejam imaginados. Frequentemente eles se vinculam ao lado clandestino e subterrâneo da vida social, mas também à arte, a qual pode às vezes surgir como um código de interpretação não-oficial. É o espaço vivido pelos usuários da cidade (moradores), artistas e pensadores.

REPRESENTAÇÕES DO ESPAÇO: o espaço concebido (espace conçu). É o espaço dominante dentro do modo de produção de cada sociedade. Esta ampla categoria mistura ideologia e conhecimento. As representações tendem a ser intelectualmente elaboradas como um sistema coerente, lógico e compreensivo de signos e códigos verbais oficiais. Em grande medida consiste no espaço comumente concebido na contemporaneidade por arquitetos, urbanistas e tecnocratas. Sua ordem pretende-se neutra, na medida em que é qualificada como técnica e científica, embora de fato sempre favoreça a alguém. As representações tendem a atribuir um lugar específico a cada atividade.

PRÁTICA ESPACIAL: o espaço percebido (espace perçu). Conjunto de presenças, ações e discursos empiricamente observáveis (visíveis e legíveis) nos espaços da vida cotidiana. A prática espacial de cada sociedade dialeticamente pressupõe um espaço ao mesmo tempo em que o gera. A prática espacial abarca produção e reprodução social. A prática espacial das sociedades capitalistas, por exemplo, é associada aos modos espaciais pelos quais as pessoas utilizam seu tempo em atividades do diaa-dia, é vinculada aos caminhos que conectam lugares de trabalho, vida privada e lazer (a separação destes espaços incluída).

A teoria acerca dos movimentos sociais urbanos (CASTELLS, 1983) assumiu especial significado para o novo paradigma. Castells combina análise estrutural - intervenção estatal para aliviar contradições do capitalismo - com uma investigação empírica a respeito dos atores coletivos locais reagindo contra as novas condições de intervenção estatal em domínios da vida cotidiana na cidade. 


\section{A mudança de paradigma em Sociologia Urbana: do paradigma ecológico ao socioespacial}

Embora o conceito de consumo coletivo possibilite manter um tênue vínculo com a produção econômica, Castells reconhece que os movimentos sociais urbanos enfatizam primordialmente questões que lhe são externas ${ }^{25}$. Portanto, seria necessário entendê-los em seus próprios termos, considerando que os integrantes de movimentos sociais urbanos são movidos por esperanças, sonhos e desejos que lhes são próprios. Lutas de caráter não-econômico politizando o espaço urbano também são fontes de conflitos sociais capazes de abastecer transformações na cidade que se opõem aos interesses das classes dominantes. Tal conclusão de certo modo faz eco às ideias de Lefebvre, com os movimentos sociais urbanos aparecendo como uma categoria que estava faltando na teoria da produção do espaço por este formulada. Ela se revela muito pertinente para designar os sujeitos coletivos contra-hegemônicos engajados em lutas sociais pelo direito à cidade. Contudo, para Castells os movimentos sociais urbano ${ }^{26}$ não são um novo proletariado em analogia àquele teorizado por Marx, já que se destinam "a transformar o significado da cidade sem terem a capacidade de transformar a sociedade" (CASTELLS, 1983; p. 327, tradução do autor).

Em fins dos anos 1980, Castells direcionou novamente seu foco de investigação em sociologia urbana ao contexto econômico. Diante da rápida disseminação de inovações tecnológicas e levando em consideração as tendências do processo de globalização, o autor sustenta que na contemporaneidade está em curso uma profunda transformação na noção de espaço (CASTELLS, 1989). O argumento de Castells é simples. O espaço constitui o suporte material para práticas sociais que compartilham tempo. Se os atores não estão presentes no mesmo espaço, eles não conseguem interagir em tempo real. Durante grande parte da história, entretanto, o único espaço que permitia compartilhar o tempo era uma lugar, um espaço físico. Tal situação mudou completamente nas últimas décadas. $\mathrm{O}$ "espaço dos lugares" não mais está sozinho, pois um novo tipo de espaço foi criado: o "espaço dos fluxos". Repentinamente, a tecnologia tornou possível manter contato no mesmo espaço temporal sem compartilhar o mesmo espaço físico. Se as instituições-chave da produção capitalista estão sendo reestruturadas a fim de se beneficiarem do "espaço dos fluxos", a revolução informacional também não deixa de alcançar a esfera de consumo coletivo da vida cotidiana (CASTELLS, 1989).

\footnotetext{
${ }^{25} \mathrm{O}$ autor constata que muitos movimentos sociais progressistas não possuem nenhuma conexão direta com as relações de trabalho internas ao processo produtivo industrial. Eles lidam na maioria das vezes com um conjunto distinto de questões, a exemplo dos movimentos ambientalista, nacionalista e feminista. Por conta disso, suas lutas podem ser consideradas não apenas complementares às tradicionais (lutas de sindicatos e partidos políticos), mas de certo modo autônomas.

${ }^{26}$ Para uma análise da evolução do conceito de movimentos sociais urbanos na obra de Castells, ver Martínez (2003).
} 


\section{HUMANAS}

As mudanças sociais em curso, tanto na esfera da produção quanto na esfera do consumo, estão afetando particularmente os espaços urbanos, afirma Castells. O "espaço de fluxos" possui uma materialidade fornecida pelo "espaço dos lugares" (infraestrutura de comunicações, aeroportos, cadeias hoteleiras). É complexo e caro criar e manter o "espaço de fluxos", assim nem todos os espaços urbanos são capazes de oferecer a materialidade exigida para se tornarem parte da rede. A constituição de novos espaços implica a existência de novas fontes de exclusão social nos centros urbanos e de estratificação entre as cidades. Grandes metrópoles, por exemplo, desempenham um papel crucial na rede, como lugares onde as pessoas se encontram e as elites se constituem. Mas nessas cidades, uma distribuição espacial particular e formas espaciais específicas definem a separação entre o território ocupado pelas elites e o território ocupado pelos pobres ("cidade dual"). Adicionalmente, o autor destaca que, após um momento inicial de refluxo (seu caráter eminentemente local havia sido desafiado pela globalização), os movimentos sociais urbanos começam a se beneficiar do "espaço de fluxos", o que poderia resultar em estratégias de luta social que articulariam os níveis de ação local e global (CASTELLS, 1989).

Desde a publicação de seu estudo contrapondo a visão liberal à visão socialista em relação à justiça social na cidade (HARVEY, 1973) marcado por uma releitura original do pensamento marxista, Harvey vem contribuindo decisivamente para o desenvolvimento do paradigma socioespacial em sociologia urbana. Ao analisar as relações entre teoria, espaço, urbanismo e justiça social, o autor reforça a premissa de que as formas espaciais da cidade não são objetos inanimados nos quais os processos sociais se desenrolam; ao contrário, as formas espaciais contêm os processos sociais da mesma maneira em que estes são intrinsecamente espaciais. Ao invés de se ocupar da questão ontológica acerca do que é o espaço, o autor move sua atenção à maneira pela qual as diferentes práticas sociais criam e fazem uso de distintas conceptualizações do espaço e de distintas formas espaciais. Nessa tarefa, ele busca romper com as tradicionais dicotomias entre fato e valor, descrição e prescrição, metodologia e filosofia nos estudos urbanos (HARVEY, 1973).

Tal qual Castells, Harvey assevera que os espaços urbanos estão ligados principalmente à esfera do consumo coletivo e identifica a luta de classes (entre o "trabalho" e "capital", assim como internamente às frações deste) como sendo um componente essencial da criação, gestão e uso do ambiente construído (casas, estradas, parques, calçadas). Alguns desses itens de consumo coletivo, diz o autor, podem ser apropriados privativamente, ao passo que os demais devem ser utilizados em comum, mas todos eles são parte das condições básicas de vida do "trabalho". O sistema de propriedade privada e a intervenção estatal, porém, tendem a excluir o "trabalho" do consumo do meio ambiente construído (HARVEY, 1982). 


\section{A mudança de paradigma em Sociologia Urbana: do paradigma ecológico ao socioespacial}

Se a cidade emerge como local da luta de classes, a outra face da moeda é seu papel funcional como unidade de acumulação de capital (HARVEY, 1989a). A relação de dominação do "capital" sobre o "trabalho" se expressa no processo de produção do espaço urbano na economia capitalista. As lutas pelos espaços urbanos contra as imposições do "capital", além de constituírem uma contenda em torno de condições básicas de vida, são também uma batalha acerca do significado do meio ambiente construído como conjunto de valores de uso para o "trabalho". Trata-se de um conflito em torno do que significa qualidade de vida na esfera do consumo: se isso significa valores de uso vantajosos para a acumulação capitalista ou se reflete reais necessidades humanas (HARVEY, 1982). Essa discussão retoma, em termos similares, a distinção de Lefebvre entre as qualidades de produto e de obra que podem marcar os espaços socialmente produzidos.

Contudo, ao concluir que, em última análise, os "conflitos no lugar da vida cotidiana são um mero reflexo da tensão subjacente entre capital e trabalho" (HARVEY, 1982; p. 557, tradução do autor), a argumentação de Harvey soa um tanto reducionista. O autor parece negar, ou ao menos relegar a um segundo plano, o fato de que as sociedades capitalistas são também compostas por outros importantes tipos de opressões (baseadas em raça, gênero, idade ou identidade étnico-cultural, por exemplo) que seguem lógicas até certo ponto autônomas no que concerne às relações de classe e que também impõem empecilhos a certos grupos quanto à sua plena participação na apropriação coletiva do espaço urbano. A ressalva não impede que se destaque a contribuição fundamental oferecida por Harvey à sociologia urbana, cujas construções teóricas vêm se revelando frutíferas na elucidação de problemas urbanos centrais, a exemplo do funcionamento dos mercados habitacionais e dos mecanismos de enobrecimento.

Ademais, a obra de Harvey permite repensar as cidades como atoreschave diante das novas demandas de produção espacial do capitalismo globalizado. É o caso do raciocínio que ele desenvolve acerca da competição entre as cidades (HARVEY, 1989b). O autor sustenta que toda cidade participa de uma disputa com as cidades pares em relação à posição a ser ocupada na divisão internacional do trabalho e do consumo. Perante esse cenário de crescente competição interurbana, os governos locais estão adotando práticas de empreendedorismo a fim de estimular o crescimento econômico e gerar novas oportunidades de emprego. De um lado, as cidades fomentam os investimentos de empresas privadas através de estratégias agressivas voltadas a derrotar as localidades adversárias na atração de negócios. De outro, articulam ambiciosos programas de desenvolvimento com a intenção de melhorar sua imagem e explorar novas oportunidades econômicas. O turismo, por exemplo, quase sempre aparece como um possível segmento para inovação. 


\section{HUMANAS}

Transformações urbanas de grande monta vêm sendo promovidas por toda parte para adequar as cidades às novas demandas do capital. A produção de atratividade urbana, entretanto, acaba por se configurar frequentemente um jogo de soma-zero. "[...] Até mesmo o mais resoluto e progressista grupo municipal de socialistas [...]", sublinha Harvey (1989b, p. 5, tradução nossa), “[...] irá se encontrar, ao final, tomando parte no jogo capitalista e desempenhando o papel de agente de ordenação dos processos em relação aos quais buscava oferecer resistência". Além de passageiro, o sucesso no empreendimento de criação de uma cidade diferenciada, capaz de efetivamente atrair o capital, pode contraditoriamente implicar a perda das qualidades que conferiam peculiaridades ao espaço urbano local. A chegada do capital e de seus produtos espaciais repetitivos, em certa medida, destrói aquilo que era único à cidade, que lhe conferia identidade e particularidade, ao passo que concretiza localmente a paisagem homogênea globalizada.

\section{Conclusão}

De acordo com a teoria de Kuhn (1962), antes que uma mudança de paradigma suceda em um dado campo científico, há um nebuloso e turbulento período de transição. Este período é marcado pela crise da ciência normal, suscitada seja por fatores internos, seja por fatores externos à prática científica. Difunde-se durante a época de transição a percepção de mau funcionamento do paradigma vigente. Por conta disso, alguns membros da comunidade de cientistas que compartilham do paradigma tendem a desenvolver formas inovadoras de prática científica que extrapolam seus confins. Paralelamente, membros de comunidades científicas distintas, mesmo desconhecendo o paradigma da comunidade em crise, sentem-se confortáveis para incursionar em temas atinentes ao objeto de saber desta a partir de seus próprios pontos de vista. Nesse processo, é possível que se estruture uma escola, isto é, uma nova comunidade científica que aborda sob uma perspectiva diferente - um paradigma emergente $-\mathrm{o}$ objeto de saber em torno do qual se estabeleceu a crise. Essa escola passa a competir com a comunidade científica que cultiva a ciência normal, tendo lugar uma disputa de hegemonia que pode redundar em uma mudança de paradigma.

Desenvolvendo-se ao longo do século XX nos países do capitalismo central enquanto um ramo disciplinar das ciências sociais voltado ao estudo do fenômeno urbano, a sociologia urbana enfrentou uma transformação radical entre as décadas de 1970 e 1980 . A teoria dos paradigmas contribui para explicar a crise e o declínio do modelo de cientificidade que até aquele momento guiava o trabalho da comunidade de sociólogos urbanos e sua repentina substituição por outro modelo emergente. A passagem do paradigma ecológico, 


\section{A mudança de paradigma em Sociologia Urbana: do paradigma ecológico ao socioespacial}

cujo advento coube à Escola de Chicago, ao paradigma socioespacial, fundado com base nas contribuições da Escola Neomarxista, provocou uma completa reviravolta na constelação de compromissos que orientava a produção de conhecimento sociológico sobre a cidade. Do arsenal de conceitos úteis, teorias confiáveis e pressupostos assumidos como fora de disputa aos problemas de pesquisa considerados significativos, nada restou imune à mudança de paradigma em sociologia urbana.

\section{Referências bibliográficas}

AZUELA, A. La ciudad, la propiedad privada y el derecho. México: El Colegio de México, 1999.

BURGESS, E. The growth of the city: an introduction to a research project. In: R. PARK \& E. BURGESS (Orgs.). The city: suggestions for investigation of human behavior in the urban environment. Chicago: University of Chicago Press, 1925.

CASTELLS, M. The informational city: information technology, economic restructuring and the urban-regional process. Oxford e Cambridge: Blackwell, 1989.

CASTELLS, M. The city and the grassroots: a cross-cultural theory of urban social movements. Berkeley: University of California Press, 1983.

CASTELLS, M. La question urbaine. Paris: Maspero, 1972.

COULON, A. L'école de Chicago. Paris: PUF, 1992.

DURKHEIM, E. Le suicide: étude de sociologie. Paris: PUF, 2007 [1897].

DURKHEIM, E. De la division du travail social. Paris: PUF, 2007 [1893].

ENGELS, F. The housing question. In: K. MARX \& F. ENGELS. Marx and Engels collected works, volume 23. New York: International Publishers, 1988 [1872].

ENGELS, F. The conditions of the working class in England. In: K. MARX \& F. ENGELS. Marx and Engels collected works, volume 4. New York: International Publishers, 1975 [1845].

GOTTDIENER, M. A Marx for our time: Henri Lefebvre and the production of space. Sociological Theory, 11(1): 129-34, 1993.

GOTTDIENER, M. The social production of urban space. Austin: University of Texas Press, 1985. 


\section{HUMANAS}

GOTTDIENER, M, \& FEAGIN, J. The paradigm shift in urban sociology. Urban Affairs Quarterly, 24(2): 163-87, 1988.

GRAFMEYER, I. \& JOSEPH, I. La ville-laboratoire et le milieu urbain. In: I. GRAFMEYER \& I.JOSEPH (Orgs.) L'école de Chicago: naissance de l'écologie urbaine. Paris: Albier, 1990.

HARVEY, D. The urban experience. Baltimore: The John Hopkins University Press, 1989a.

HARVEY, D. From managerialism to entrepreneurialism: the transformation in urban governance in late capitalism. Geografiska Annaler, 71(1): 3-17, 1989 b.

HARVEY, D. Labour, capital, and class struggle around the built environment in advanced capitalist societies. In: A. GIDDENS \& D. HELD (Orgs.). Classes, power, and conflict: classical and contemporary debates. London: MacMillan, 1982.

HARVEY, D. Social justice and the city. London: Edward Arnold, 1973.

HAWLEY, A. Human Ecological and Marxian Theories. The American Journal of Sociology, 89(4): 904-17, 1984.

HESS, R. Henri Lefebvre et l'aventure du siècle. Paris: Editions A. M. Métailié, 1988.

JACOBS, J. The death and life of great American cities. New York: Vintage Books, 1961.

JARET, C. Recent Neo-Marxist Urban Analysis. Annual Review of Sociology, 9: 499-525, 1983.

KATZNELSON, I. Marxism and the city. Oxford: Oxford University Press, 1993.

KUHN, T. A estrutura das revoluções científicas. Tradução: B. Boeira \& N. Boeira. São Paulo: Perspectiva, 2003 [1962].

KUKLICK, H. Chicago sociology and urban planning policy: sociological theory as occupational ideology. Theory and Society, 9(6): 821-45, 1980.

LEFEBVRE, H. Du rural à l'urbain. Paris: Anthropos, 2001 [1970a].

LEFEBVRE, H. La production de l'espace. Paris: Anthropos, 2000 [1974].

LEFEBVRE, H. Espace et politique: le droit à la ville II. Paris: Anthropos, $2000[1973]$. 
LEFEBVRE, H. La pensée marxiste et la ville. Paris/Tournai: Casterman, 1972.

LEFEBVRE, H. La révolution urbaine. Paris: Gallimard, 1970b.

LEFEBVRE, H. Le droit à la ville. Paris: Anthropos, 1973 [1968].

MARTINEZ LOPEZ, M. Los movimientos sociales urbanos: un análisis de la obra de Manuel Castells. Revista Internacional de Sociología, 34: 83-106, 2003.

MCKENZIE, R. The ecological approach to the study of the human community. In: R. PARK \& E. BURGESS (Orgs.) The city: suggestions for investigation of human behavior in the urban environment. Chicago: University of Chicago Press, 1925.

MERRIFIELD, A. Metromarxist: a Marxist tale of the city. New York: Routledge, 2002.

PARK, R. The mind of the hobo: reflections upon the relation between mentality and locomotion. In: R. PARK \& E. BURGESS (Orgs.) The city: suggestions for investigation of human behavior in the urban environment. Chicago: University of Chicago Press, 1925.

SIMMEL, G. The stranger. In: K. WOLFF (Org.) The sociology of Georg Simmel. Glencoe: Free Press, 1950a.

SIMMEL, G. The metropolis and mental life. In: K. WOLFF (Org.) The sociology of Georg Simmel. Glencoe: Free Press, 1950b.

STADER, F. Manuel Castells: the theory of the network society. Cambridge: Polity Press, 2006.

STÉBÉ, J. \& MARCHAL, H. La sociologie urbaine. Paris: PUF, 2007.

TUCKER, K. \& TUCKER JR., K. Classical social theory: a contemporary approach. Oxford: Blackwell, 2001.

WALTON, J. Urban sociology: the contributions and limits of political economy. Annual Review of Sociology, 19: 301-20, 1993.

ZUKIN, S. A decade of the new urban sociology. Theory and Society, 9(4): 575-601, 1980. 